\title{
Use of a Combined Technology of Ultrasonication, Three-Phase Partitioning, and Aqueous Enzymatic Oil Extraction for the Extraction of Oil from Spirogyra sp.
}

\author{
Adisheshu Reddy and Abir B. Majumder \\ Department of Chemistry, Rajiv Gandhi University of Knowledge Technologies, Basar, Andhra Pradesh 504107, India \\ Correspondence should be addressed to Abir B. Majumder; aabir.majumder@gmail.com
}

Received 6 August 2014; Accepted 17 October 2014; Published 13 November 2014

Academic Editor: Bing Wang

Copyright (C) 2014 A. Reddy and A. B. Majumder. This is an open access article distributed under the Creative Commons Attribution License, which permits unrestricted use, distribution, and reproduction in any medium, provided the original work is properly cited.

\begin{abstract}
Algal oil from Spirogyra sp. was extracted using a combined technology of ultrasonication, three-phase partitioning, and aqueous enzymatic oil extraction. Ultrasonication was done to rupture the cell wall and papain was used for an easier release of the trapped oil. The salt concentration for three-phase partitioning, preincubation period with (or without) the protease, and its operational temperature were optimized for a maximum possible yield of the oil and the effect of ultrasonication, and three-phase partitioning with (or without) the protease were studied. It was found that under optimized conditions at $50 \%$ ammonium sulphate concentration using tert-butanol (in $1: 1, \mathrm{v} / \mathrm{v}$ ratio) a presonicated and papain treated algal suspension could produce $24 \%$ (w/w, dry weight) oil within few hours which was ten times higher as compared to the oil obtained by Soxhlet extraction using hexane and two times higher than the oil obtained without using the protease.
\end{abstract}

\section{Introduction}

In past few decades preparation of biofuels from the waste materials has been a matter of great interest [1-3]. A more recent alternative which has been in focus for acting as a source of oil is algae $[1,2,4]$. The algae which have been found most effective as triacylglycerols (TAG) source are microalgae. Depending upon the species and the extraction process, the TAG content (\%, dry weight of the algae) in microalgae can reach beyond $90 \%$ which is much higher than the reported values (20-30\%) for macroalgae [5-7]. However, extraction of oil from macroalgae has continued to be a matter of research $[4,5,8]$. In the present work Spirogyra sp. has been evaluated as the source of oil. Apart from its widespread availability one attractive feature of Spirogyra cell is its simple cell wall which can be easily ruptured [9]. Hence the algae need more attention and should be explored with advanced technologies which speed up the extraction process and improve the yield of the oil.

One of the recent techniques which has been attractive to the scientists for oil extraction is the use of Three-Phase
Partitioning (TPP) [10-12]. Three-Phase Partitioning (TPP) uses tert-butanol and ammonium sulfate to precipitate enzymes and proteins from aqueous solutions. TPP can be used effectively with crude samples and can be easily scaled up. tert-Butanol seems to bind with TPP-precipitated proteins which are actually protein-tert-butanol coprecipitates float in between organic and aqueous layer. Buoyancy of this protein bound tert-butanol above the denser saline aqueous medium and presence of sulphate ion in large concentration and its kosmotropic action assisted by tertbutanol are responsible for its effectiveness [13]. The process thus helps in the separation of the lipid content from the protein and its extraction to the upper organic layer. This virtue of TPP has been utilized to separate lipids from protein, in protein purification, and in oil extraction $[13,14]$. tertButanol, being a borderline solvent exhibiting hydrophilicity and also a degree of hydrophobicity, helps in abstraction of the hydrophobic lipids from aqueous layer into the organic layer. Besides TPP two other important tools which are often found fruitful (while applying one or both in a single process) in oil extraction are ultrasonication and aqueous enzymatic 
oil extraction [11, 15-18]. Among the various technologies available to increase the oil yield, one of the more recent strategies is AEOE, aqueous enzymatic oil extraction [1518]. In this process the enzymes, chiefly hydrolases, help in an easy release of the trapped oil. Proteases are one of the commonly used enzymes in AEOE. In the present work we have chosen papain for the purpose. The reason is its temperature tolerance and easy availability and that it is cheap. A very important aspect of process engineering is "cost effectiveness" and use of papain fits in it well. However, the use of papain in AEOE is not new. Sharma et al. have shown purified papain very much effective in AEOE from peanut [16]. A recent study shows the use of papain to extract oil from microalgae [19] but nobody so far, to the best of our knowledge, has tried papain for macroalgae like Spirogyra. In this connection it is worth mentioning that a recent study shows that the lipid droplets in Spirogyra cells are environmentally similar to the lipids found in seeds [20]. In this work, for the first time, we show that TPP coupled with ultrasonication and AEOE can be applied to green algae (Spirogyra sp., abundant in southern part of India) for the efficient extraction of algal oil.

\section{Experimentals}

2.1. Materials. Hexane ( $>99 \%$, GC grade), Tertiary butanol (2-methyl-2-propanol, 99\%), and anhydrous sodium sulphate (99\%) were purchased from Fischer Scientific, Qualigens Fine Chem, Mumbai, India. Ammonium sulphate (>99\%) was brought from SD Fine Chemicals ltd, Tarapur, India.

2.2. Algae Production Condition and Harvesting. The campus water reservoir containing rain water was used for algae production. The model may be taken as an unnatural cemented open pond (covered with a net) where the algal biomass was allowed to grow. The temperature of the reservoir water was found to show fluctuation within $20-40^{\circ} \mathrm{C}$ throughout a day. The algae were collected by the use of wired mesh and were fragmented mechanically by crushing with a hand roller. The fragmented resized algal mass (area $\sim 0.3 \times 0.3 \mathrm{~cm}^{2}$ ) was collected from under the mesh. The mass was then suspended in clean water and was filtered. The cleaned residue was used for further experiments.

2.3. Soxhlet Extraction. In a Soxhlet apparatus $200 \mathrm{~g}$ of fresh cleaned algae was taken and extracted with a solution of hexane for a period of $12 \mathrm{~h}$. The extract was evaporated under vacuum at $40^{\circ} \mathrm{C}$ and the yield of the oil was noted.

2.4. Ultrasonication. In a separate set, $200 \mathrm{~g}$ of algae was suspended in water and was given a treatment of ultrasonication (in Wenser WUC series) at $40 \mathrm{KHz}$ for a varied time period of $30 \mathrm{~min}-2 \mathrm{~h}$ at $30^{\circ} \mathrm{C}$. This sonicated sample along with the control was then taken for the next stage of experiments for oil extraction.

2.5. Three-Phase Partitioning. In a screw capped bottle $200 \mathrm{~g}$ of crushed sample algae (sonicated or control) was taken in distilled water and the solution was made up to $250 \mathrm{~mL}$. Ammonium sulphate was added in varied amounts (20$90 \%, w / v$ ) to the algal suspension (sonicated or control) with continuous stirring followed by the addition of tert-butanol (in $1: 1 \mathrm{v} / \mathrm{v}$ ). The biphasic sample solution was set on magnetic stirring at $40^{\circ} \mathrm{C}$ for $4 \mathrm{~h}$ and then it was incubated without stirring for $6 \mathrm{~h}$. A three-phase partitioning was observed with a lower aqueous phase and upper organic phase with the cell debris (and/or protein) lying in between the two phases. The organic layer was separated carefully after centrifugation at $5000 \times \mathrm{g}$ using pipettes and was dried by anhydrous sodium sulphate. The dry organic layer was evaporated under strong vacuum at $40^{\circ} \mathrm{C}$ and the oil was collected as the residual fluid. The green oil was stored in sealed vials and used for the next stage. The fine particulate matters in the oil were removed by a high speed centrifugation at $8000 \times \mathrm{g}$ for $10 \mathrm{~min}$.

2.6. Aqueous Enzymatic Oil Extraction. To the aqueous buffer solution of algae $(0.1 \mathrm{M}$, phosphate buffer, $\mathrm{pH}$ 6) papain formulation (prepared as mentioned in the next section) was added $(2 \mathrm{~g})$ and then incubated at $40^{\circ} \mathrm{C}$ with magnetic stirring over a period of $2-10 \mathrm{~h}$. The enzyme treated suspension was then subjected to TPP.

2.7. Preparation of Papain Formulation for Oil Extraction. Preparation of solid papain formulation was made following a precipitation technique reported by Baines and Brocklehurst [21] with a little modification; instead ammonium sulphate acetone was used. Afterwards, it has been shown that acetone can be an efficient solvent for this purpose [22]. The latex obtained from the fresh longitudinal cuts of raw papaya (Carica papaya) was collected and immediately dissolved in buffer solution $(0.1 \mathrm{M}, \mathrm{pH} 6,1: 3 \mathrm{v} / \mathrm{v})$ in cold. The solution was transferred in ice chilled dry acetone ( $5 \mathrm{x} \mathrm{v} / \mathrm{v}$, buffer) and was allowed for $30 \mathrm{~min}$ in ice bucket for complete precipitation. The precipitate was collected by mild centrifugation and was air-dried. The activity of this solid precipitate was checked after dissolving it in same buffer solution at $35^{\circ} \mathrm{C}$. From this solid mass, $2 \mathrm{~g}$ solid (100 units) was taken and further experiments were performed [23].

\section{Results and Discussion}

Scheme 1 shows the flow sheet for the preparation of algal oil. Immediately after sonication, as described in the methods, Section 2.5, the suspension was subjected to TPP and was centrifuged and the oil was recovered. The weight and the volume were noted and the density was calculated, $d=$ $0.89 \mathrm{~g} \mathrm{~mL}^{-1}$. The yield of the oil was expressed in terms of $\% \mathrm{w} / \mathrm{w}$ (dry weight of the algae). In this connection it is worth mentioning that $200 \mathrm{~g}$ of wet algal sample after drying gave $45 \mathrm{~g}$ of dry mass. An attempt was made to optimize the process to maximize the oil yield.

3.1. Effect of the Variation of Salt Concentration during TPP on Oil Yield. As a part of usual practice, the salt concentration (saturation percentage) was varied. Figure 1 shows the results of this variation. A sharp decrease in oil yield was observed 


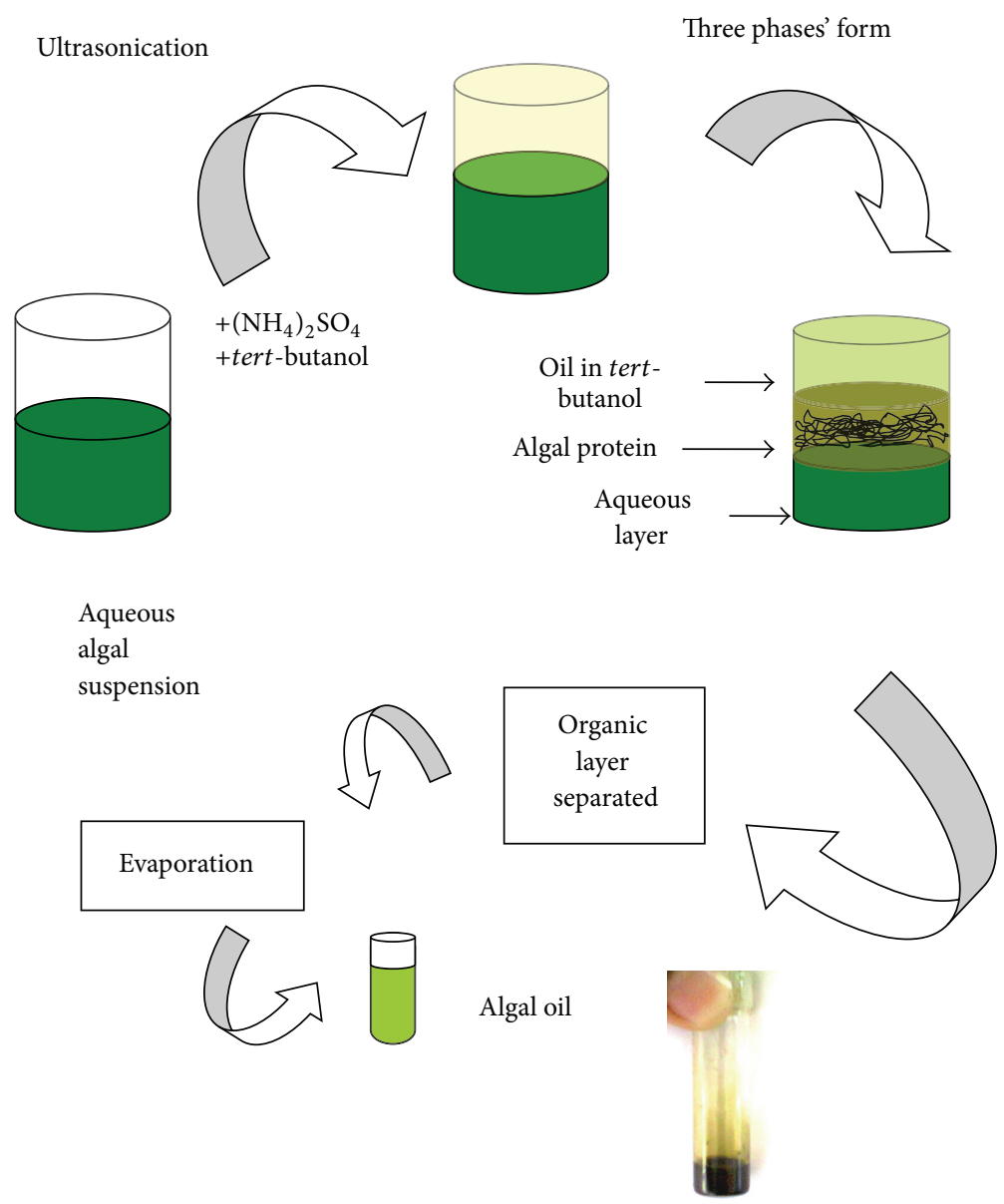

Scheme 1: Extraction of algal oil by Three-Phase Partitioning (TPP).

with a salt concentration $<30 \%$. An increase in the yield was observed after $40 \%$ ammonium sulphate concentration and it reached $9 \% \mathrm{w} / \mathrm{w}$ in between $50 \%$ and $60 \%$ and almost remained flat up to $70 \%$. A slight decrease was observed when a too high concentration of the salt was taken $(>80 \%)$. Based upon these experimental results 50\% ammonium sulphate concentration was screened for further experiments. Thus this optimization appears very important to choose the minimum concentration of ammonium sulphate which could give a maximum possible yield of oil. However, at this stage, the effect of ultrasonication on both Soxhlet extraction and on TPP was studied.

3.2. Effect of Ultrasonication on Oil Yield. Table 1 shows that ultrasonication treatment before Soxhlet extraction increased the oil yield by $2 \mathrm{x}$ (entries 1,2 ) while the sonicated mass after TPP gives an oil which was 10x higher (entry 5) to the oil obtained by Soxhlet extraction (after ultrasonication, entry 2) and nearly $3 x$ higher as compared to the oil obtained by TPP with a nonsonicated sample (entry 4). It indeed reflects that the effect of sonication was very much positive. In this connection it is worth mentioning that ultrasonication has been a widely used process to rupture the cell wall $[4,7$, 11, 17]. During ultrasonic treatment cavitation occurs inside
TABLE 1: Effect of ultrasonication on oil yield by Soxhlet extraction and by TPP. The algal suspension was sonicated, filtered, and subjected to Soxhlet extraction with hexane or TPP as described in the methods, Section 2.5. Each set was run in triplicate and the variation between the experimental data was within $2 \%$.

\begin{tabular}{lccc}
\hline Entry & Process & $\begin{array}{c}\text { Sonication } \\
\text { time }(\mathrm{h})\end{array}$ & (Yield \%, w/w) \\
\hline 1 & $\begin{array}{c}\text { Soxhlet extraction } \\
2\end{array}$ & 0 & 1.8 \\
3 & $\begin{array}{c}\text { Ultrasonication + Soxhlet } \\
\text { extraction }\end{array}$ & 0.5 & 3.5 \\
4 & $\begin{array}{c}\text { Ultrasonication + Soxhlet } \\
\text { extraction }\end{array}$ & 2 & 4.0 \\
5 & TPP & 0 & 4 \\
6 & Ultrasonication + TPP & 0.5 & 11 \\
\hline
\end{tabular}

the solution and around it with a sudden change in pressure the bubbles collapse and if it occurs near cell walls, the wall is broken and the cell contents are released [7]. Thus the duration of ultrasonic treatment is an important parameter for an efficient release of the oil. In the present work it was found that sonication for an increased time period up to $2 \mathrm{~h}$ 


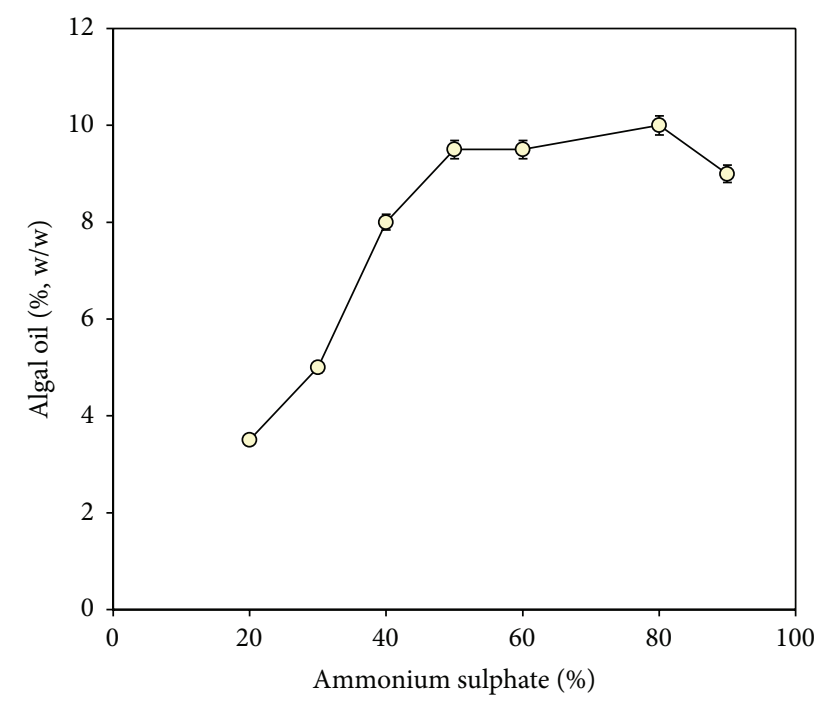

FIGURE 1: Effect of change in concentration of ammonium sulphate during TPP on oil yield (\%,w/w). The aqueous algal suspension was ultrasonicated and was subjected to TPP at $40^{\circ} \mathrm{C}$ as described in the methods, Section 2.5. Ammonium sulphate concentration was varied $(\%, w / v)$ and in each case the oil obtained was expressed in terms of $\%, w / w$, dry weight of algae. Each set was performed in triplicate and the deviation between the sets of experimental data was within $2 \%$.

could marginally increase this yield from 1 to $1.5 \%$ (entries $3,6)$ and hence for making the process more energy-efficient and less time-consuming we restricted sonication period for 30 min only.

\subsection{Aqueous Enzymatic Oil Extraction and TPP}

3.3.1. Effect of Incubation Time with Papain. Figure 2 shows the effect of a preincubation (before TPP) of the presonicated aqueous algal suspension with or without papain at $\mathrm{pH} 6$, for a varied range of time, at $40^{\circ} \mathrm{C}$. A significant increase was observed in the yield when the incubation period was increased from 0 to $4 \mathrm{~h}$ resulting in a yield from $12 \%$ to $18 \%$ w/w. A marginal increase ( $1 \%)$, however, was observed when the contact time was extended up to $10 \mathrm{~h}$. The control, that is, the suspension without enzyme, could yield only $<12 \%(w / w)$ oil even after $10 \mathrm{~h}$ of incubation. Encouraged by this result, the temperature of the incubation with protease was varied.

\subsubsection{Effect of Incubation Temperature on Papain Assisted Oil}

Yield. Table 2 shows the effect of increase in the temperature of incubation with or without papain before TPP and after ultrasonication. Interestingly, the yield of the oil increased with an increase in temperature. An optimum was observed near $60^{\circ} \mathrm{C}$ (entry 4 , Table 2 ) which is eventually also close to the optimum temperature of papain [22] and $27 \% \mathrm{w} / \mathrm{w}$ oil could be extracted. The increase was low in case of the control as compared to the papain treated sample.

3.4. Effect of TPP on Papain. TPP itself has been found to be involved in improving the catalytic activity of enzymes by

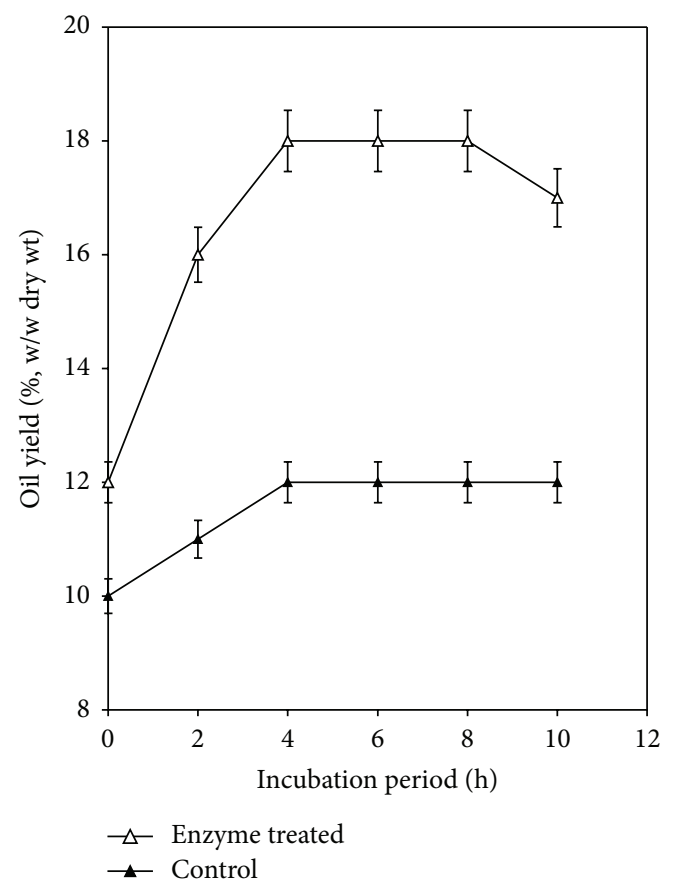

FIGURE 2: Effect of the use of papain on oil yield. The algal suspension was given a treatment of ultrasonication as described in the method section and was incubated at $40^{\circ} \mathrm{C}$ with crude papain $(2 \mathrm{~g})$ at $\mathrm{pH} 6$ with magnetic stirring along with a control (without enzyme) and then a Three-Phase Partitioning was done as described before with $50 \%$ ammonium sulphate. In each case the yield of the oil was expressed in w/w, dry weight of the algae. Each set was performed in triplicate and the deviation between the experimental data was within $3 \%$.

TABLE 2: Effect of temperature on papain assisted oil extraction (by TPP). The sonicated aqueous suspension of algae containing $2 \mathrm{~g}$ of crude papain (100 units) was incubated at $\mathrm{pH} 6$ at different temperatures for $6 \mathrm{~h}$ as optimized earlier and it was subjected to three-phase partitioning. The control was the suspension without enzyme. The yield of the oil in each case was noted and expressed in terms of $\%, w / w$, dry weight of algae.

\begin{tabular}{lccc}
\hline Entry & Temp & $\begin{array}{c}\text { Control (TPP) } \\
\text { (yield \%, w/w) }\end{array}$ & $\begin{array}{c}\text { Papain + TPP } \\
\text { (yield \%, w/w) }\end{array}$ \\
\hline 1 & $30^{\circ} \mathrm{C}$ & 9 & 14 \\
2 & $40^{\circ} \mathrm{C}$ & 11 & 18 \\
3 & $50^{\circ} \mathrm{C}$ & 12 & 22 \\
4 & $60^{\circ} \mathrm{C}$ & 12.5 & 27 \\
5 & $70^{\circ} \mathrm{C}$ & 13 & 25 \\
\hline
\end{tabular}

changing its conformational features (and/or by purification) [16-18]. To make sure whether the action of papain was also influenced by TPP, a control was run. This control was an AEOE under similar conditions, using papain (in $0.1 \mathrm{M}$ phosphate buffer, $\mathrm{pH} 6)$ at $60^{\circ} \mathrm{C}$ and extracted in tertbutanol saturated with ammonium sulphate in a biphasic medium. Saturation with ammonium sulphate was done, by equilibrating tert-butanol with $50 \%$ ammonium sulphate solution overnight, to maintain nearly the same polarity 


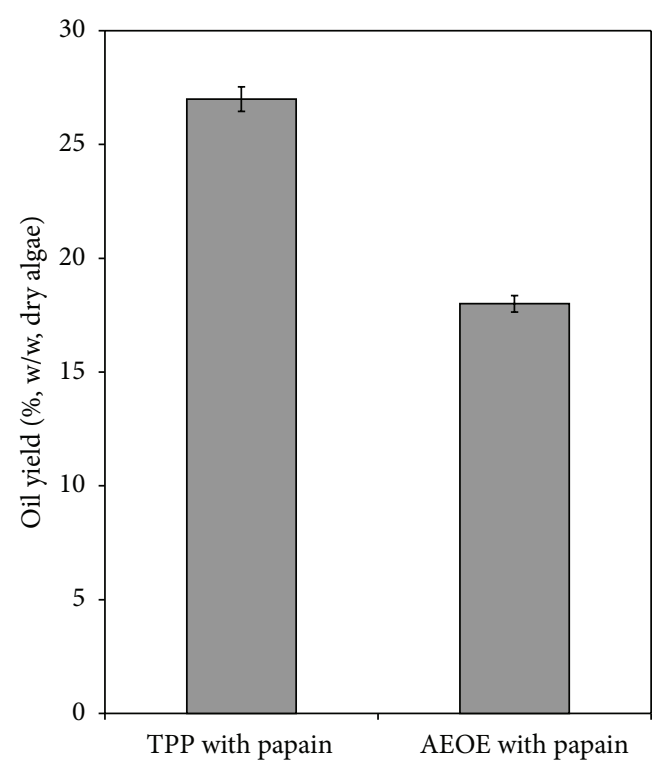

FIGURE 3: Activation of papain by TPP. The effectiveness of papain (present during the course of TPP) was measured in terms of oil yield with a control. The control was an AEOE under similar conditions. The presonicated algal suspension was incubated with papain at $\mathrm{pH}$ 6 at $60^{\circ} \mathrm{C}$ for $6 \mathrm{~h}$ and then the oil was extracted in $t$-butanol saturated with ammonium sulphate in a biphasic medium. Each experimental set was run in triplicate and the variation in the data was within $3 \%$.

as the $t$-butanol which was used in TPP. Figure 3 shows that the difference was significant. Papain (used as control in AEOE) could produce only $18 \%$ (w/w, dry algae) oil as compared to the oil obtained by the papain which was in the suspension during the process of TPP. The higher efficiency of TPP treated papain could be a combined effect of a partial purification and a conformational change and is subjected to further studies which was left for future research.

In this connection it can be added that the yield of the oil (27\%, w/w dry algae) in our case is marginally higher to the value reported by Hossain et al. which was close to $23 \%$ [5]. However, we found, in our case with our sample, the yield could never reach this value without TPP.

\section{Conclusion}

The present work shows, for the first time, that Three-Phase Partitioning can be a very effective tool for the extraction of algal oil. Use of papain as the biocatalyst was found to increase the oil yield up to $27 \%$ (w/w, dry algae). Thus $45 \mathrm{~g}$ of dry algal mass (or $200 \mathrm{~g}$ of wet algal sample) could produce $12 \mathrm{~g}$ of oil. As a part of process engineering, optimizations of salt concentration, incubation period, sonication time, and operational temperature have been done to make the entire design cost effective and efficient for algal oil extraction. The tert-butanol used in TPP could be recovered and reused up to the 5th cycle. It can be added that the extraction of the lipid has been found more effective with solvent mixtures containing a polar and a nonpolar solvent. In these cases, the polar solvent releases the lipids from their proteinlipid complexes, and the lipids subsequently dissolve in the nonpolar solvent. tert-Butanol in TPP can play a part of both.

\section{Conflict of Interests}

The authors declare that there is no conflict of interests regarding the publication of this paper.

\section{Acknowledgments}

The work was supported from the funds dedicated for Institute research, IIIT Basar, Rajiv Gandhi University of Knowledge Technologies, India. The authors thank the administration ( $R \& D$ unit) for their encouraging hand during the execution of this project. The authors are grateful to Professor M. N. Gupta, Indian Institute of Technology Delhi, for his inspiring words during this work.

\section{References}

[1] E. G. Shay, "Diesel fuel from vegetable oils: status and opportunities," Biomass and Bioenergy, vol. 4, no. 4, pp. 227-242, 1993.

[2] J. W. Lee, Advanced Biofuels and Bioproducts, Springer, NewYork, NY, USA, 2013.

[3] R. Kasirajan, S. Pandian, S. Tamilarasan, and R. Sahadevan, "Lipid extraction from natural plant source of Adenanthera pavonina using mixed solvent by superheated extractor," Korean Journal of Chemical Engineering, vol. 31, no. 3, pp. 509-513, 2014.

[4] T. Suganya, R. Kasirajan, and S. Renganathan, "Ultrasoundenhanced rapid in situ transesterification of marine macroalgae Enteromorpha compressa for biodiesel production," Bioresource Technology, vol. 156, pp. 283-290, 2014.

[5] A. B. M. S. Hossain, A. Salleh, A. N. Boyce, P. Chowdhury, and M. Naqiuddin, "Biodiesel fuel production from algae as renewable energy," American Journal of Biochemistry and Biotechnology, vol. 4, no. 3, pp. 250-254, 2008.

[6] E. Ryckebosch, K. Muylaert, and I. Foubert, "Optimization of an analytical procedure for extraction of lipids from microalgae," Journal of the American Oil Chemists' Society, vol. 89, no. 2, pp. 189-198, 2012.

[7] P. Mercer and R. E. Armenta, "Developments in oil extraction from microalgae," European Journal of Lipid Science and Technology, vol. 113, no. 5, pp. 539-547, 2011.

[8] S. Gupta, R. Sharma, S. K. Soni, and S. Sharma, "Biomass utilization of waste algal consortium for extraction of algal oil," Journal of Algal Biomass Utilization, vol. 3, pp. 34-38, 2012.

[9] F. S. Eshaq, M. N. Ali, and M. K. Mohd, "Spirogyra biomass a renewable source for biofuel (bioethanol) production," International Journal of Engineering Science and Technology, vol. 2, pp. 7045-7054, 2010.

[10] A. Sharma, S. K. Khare, and M. N. Gupta, "Three phase partitioning for extraction of oil from soybean," Bioresource Technology, vol. 85, no. 3, pp. 327-329, 2002.

[11] A. Sharma and M. N. Gupta, "Oil extraction from almond, apricot and rice bran by three-phase partitioning after ultrasonication," European Journal of Lipid Science and Technology, vol. 106, no. 3, pp. 183-186, 2004.

[12] S. Shah, A. Sharma, and M. N. Gupta, "Extraction of oil from Jatropha curcas L. seed kernels by enzyme assisted three phase 
partitioning," Industrial Crops and Products, vol. 20, no. 3, pp. 275-279, 2004.

[13] C. Dennison and R. Lovrien, "Three phase partitioning: concentration and purification of proteins," Protein Expression and Purification, vol. 11, no. 2, pp. 149-161, 1997.

[14] S. Raghava, B. Barua, P. K. Singh et al., "Refolding and simultaneous purification by three-phase partitioning of recombinant proteins from inclusion bodies," Protein Science, vol. 17, no. 11, pp. 1987-1997, 2008.

[15] A. Rosenthal, D. L. Pyle, and K. Niranjan, "Aqueous and enzymatic processes for edible oil extraction," Enzyme and Microbial Technology, vol. 19, no. 6, pp. 402-420, 1996.

[16] A. Sharma, S. K. Khare, and M. N. Gupta, "Enzyme-assisted aqueous extraction of peanut oil," Journal of the American Oil Chemists' Society, vol. 79, no. 3, pp. 215-218, 2002.

[17] S. Shah, A. Sharma, and M. N. Gupta, "Extraction of oil from Jatropha curcas L. seed kernels by combination of ultrasonication and aqueous enzymatic oil extraction," Bioresource Technology, vol. 96, no. 1, pp. 121-123, 2005.

[18] L. C. Dickey, D. B. Johnston, M. J. Kurantz, A. McAloon, and R. A. Moreau, "Modification of aqueous enzymatic oil extraction to increase the yield of corn oil from dry fractionated corn germ," Industrial Crops and Products, vol. 34, no. 1, pp. 845-850, 2011.

[19] I. Horst, B. M. Parker, J. S. Dennis, C. J. Howe, S. A. Scott, and A. G. Smith, "Treatment of Phaeodactylum tricornutum cells with papain facilitates lipid extraction," Journal of Biotechnology, vol. 162, no. 1, pp. 40-49, 2012.

[20] N. L. Huang, M.-D. Huang, T.-L. Chen, and A. H. C. Huang, "Oleosin of subcellular lipid droplets evolved in green algae," Plant Physiology, vol. 161, no. 4, pp. 1862-1874, 2013.

[21] B. S. Baines and K. Brocklehurst, "A necessary modification to the preparation of papain from any high-quality latex of Carica papaya and evidence for the structural integrity of the enzyme produced by traditional methods," Biochemical Journal, vol. 177, no. 2, pp. 541-548, 1979.

[22] E. M. Frenkel, "Studies on enzyme action: XV. Factors influencing the proteolytic activity of papain," The Journal of Biological Chemistry, vol. 31, pp. 201-215, 1917.

[23] H. Bisswanger, Practical Enzymology, Wiley-VCH Verlag Gmbh, Weinheim, Germany, 2004. 

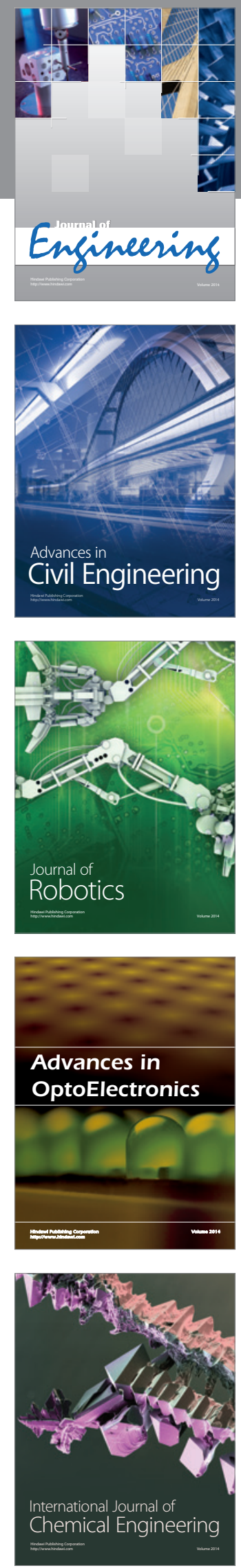

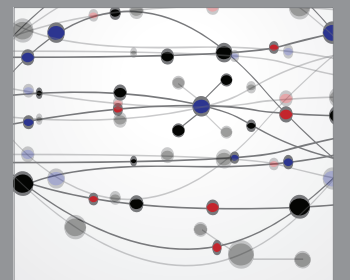

The Scientific World Journal
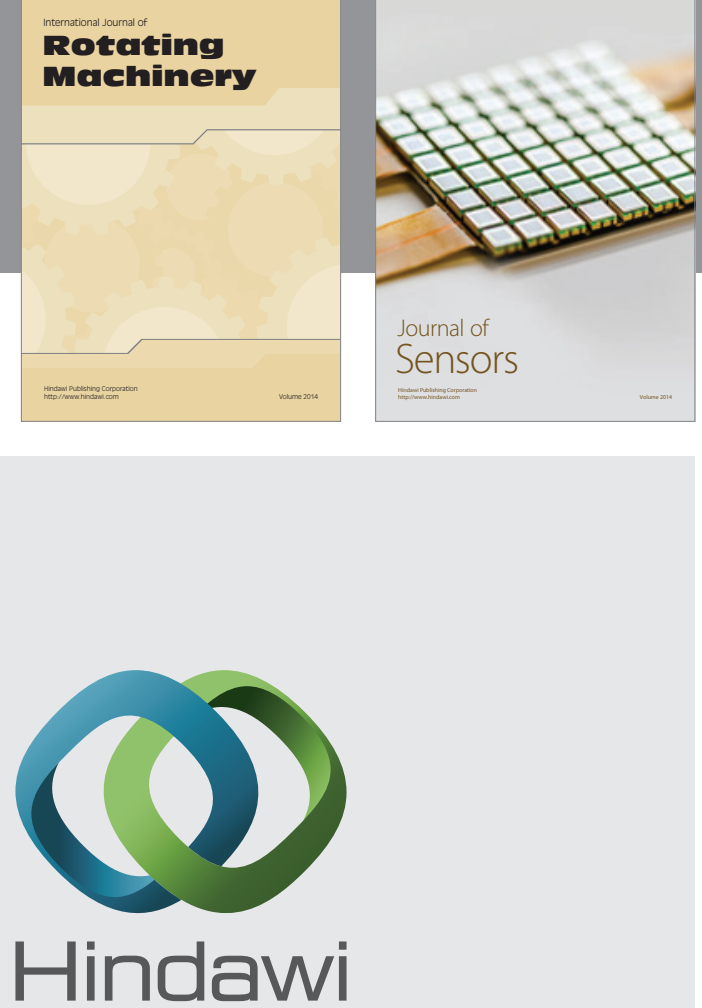

Submit your manuscripts at http://www.hindawi.com
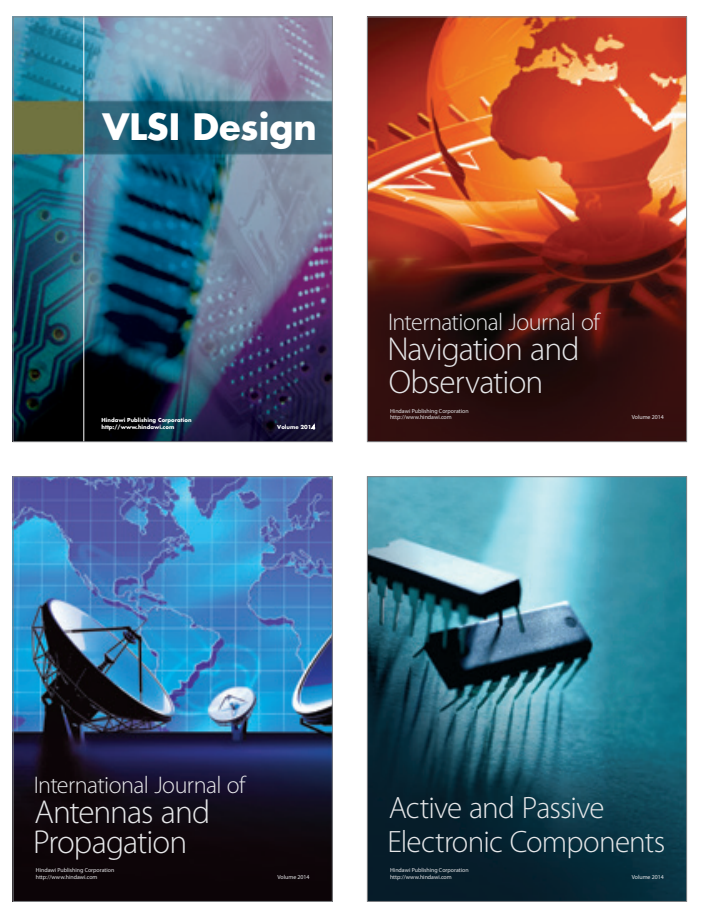
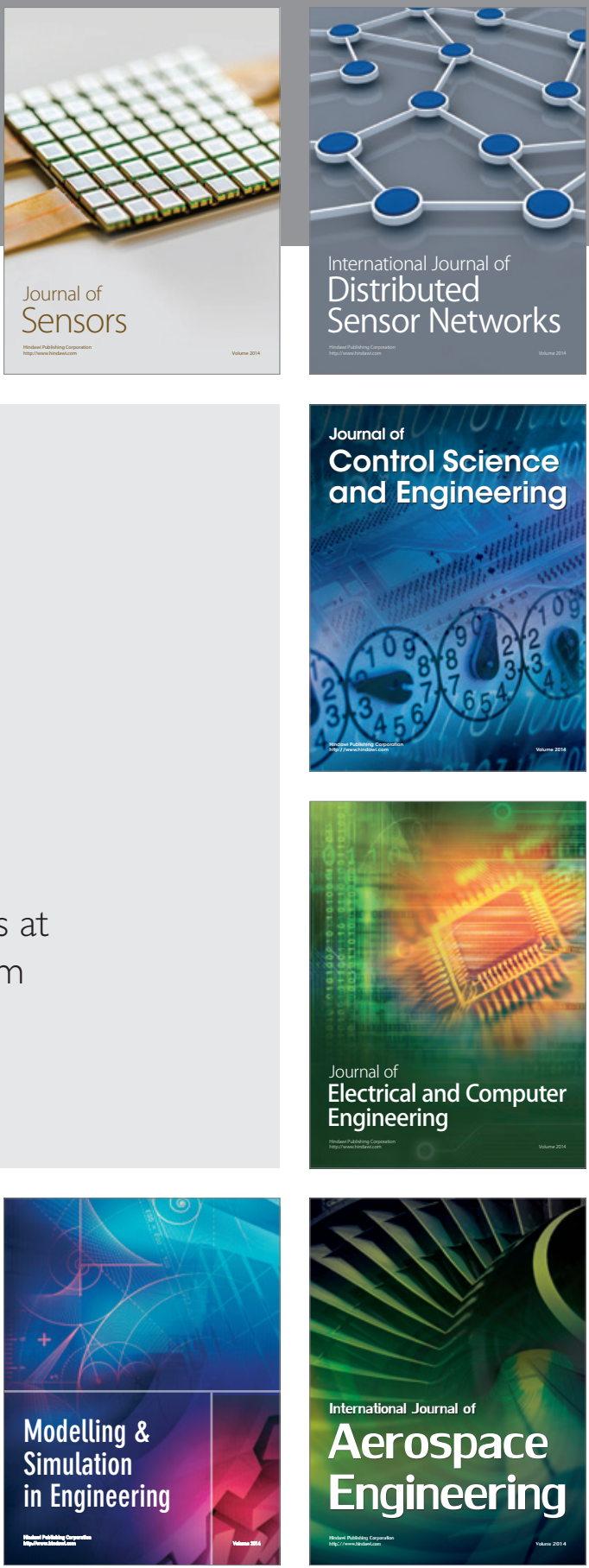

Journal of

Control Science

and Engineering
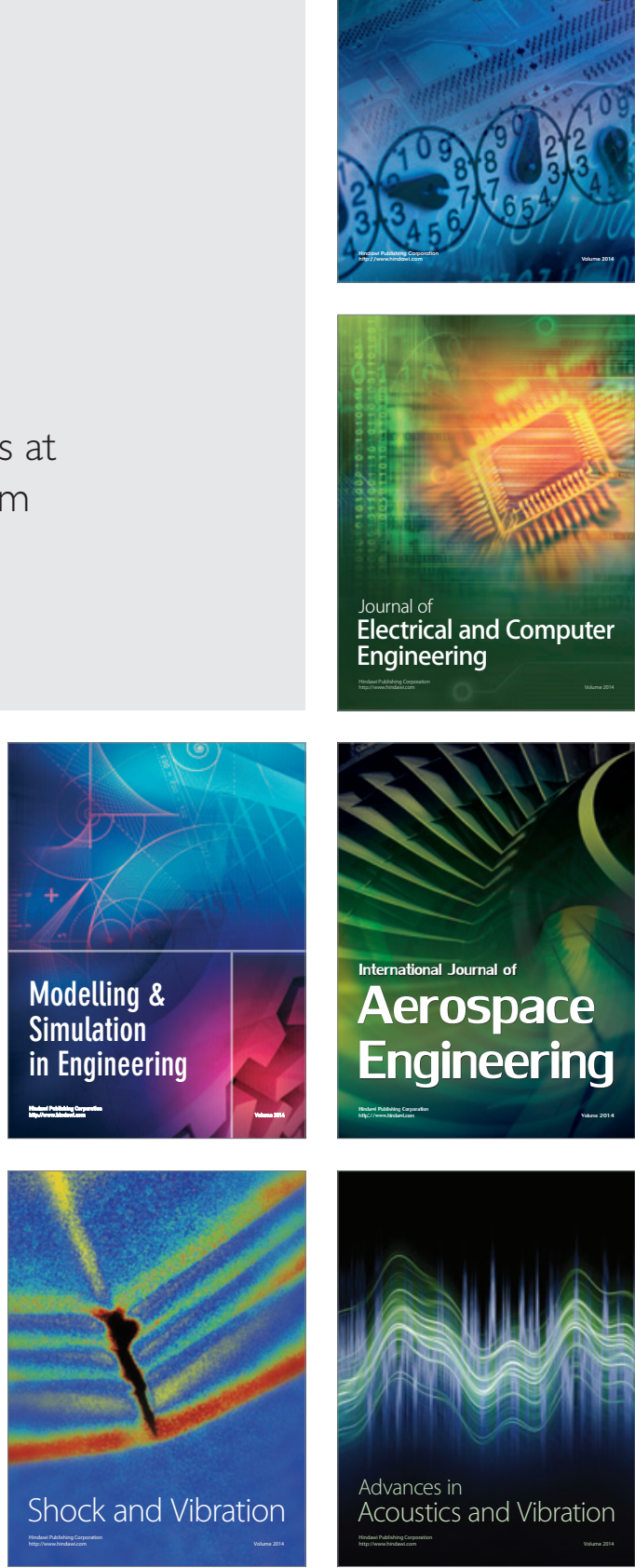